\title{
The management of extremely preterm infants
}

\author{
Fabio Mosca*, Mariarosa Colnaghi, Monica Fumagalli \\ From 70th Congress of the Italian Society of Pediatrics, Joint National Meeting SIP, SICuPP, SITIP \\ Palermo, Italy. 11-14 June 2014
}

Extreme prematurity is associated with an increased risk of mortality, morbidities and long-term neurodevelopmental impairment.

Optimizing prenatal, perinatal and postnatal care is essential to improve long-term outcome of extremely preterm babies.

Intrauterine growth restriction (IUGR) has been associated with a poorer neurological outcome and prenatal care should aim to an optimal balance between minimizing fetal injury or death versus the risks of iatrogenic preterm delivery. In the clinical phase of IUGR, hemodynamic adaptation occurs with blood flow redistribution preferentially to the brain, the so-called "brain sparing effect". However, controversy remains as to whether "brain-sparing" indicates a higher risk of brain injury or is a protective mechanism [1].

The mechanisms underlying fetal growth restriction, also determine a limitation of lung growth and maturation, thus making the lung more vulnerable to postnatal damage and increasing the risk of bronchopulmonary dysplasia (BPD), the most significant respiratory complication of prematurity [2]. Current evidence suggests that the risk of BPD may be partially related to other antenatal factors as choriamniositis (CA), which is a leading cause of very preterm delivery. Whereas CA promotes lung maturation, mediated by prenatal inflammation mechanisms, and thereby decreases the severity of respiratory distress syndrome, it also seems to increase the risk of $\mathrm{BPD}$, making the lung more susceptible to subsequent postnatal insults [3].

Neonatal resuscitation and postnatal management during the first minutes of life also play an important role in determining early and long-term outcome of VLBW. A multifaced intervention in respiratory care in the delivery room immediately after birth, including a sustained lung inflation procedure and a non invasive

\footnotetext{
NICU, Fondazione IRCCS Ca' Granda - Ospedale Maggiore Policlinico,
} Università degli Studi di Milano, Milan, Italy starting ventilation, seems to be effective in improving respiratory outcome [4].

Delayed umbilical cord clamping has received increasing attention in the management at birth of preterm infants as it seems to be beneficial and safe, being associated with less delivery room resuscitation interventions, improved haemodynamic stability and decreased rates of intraventricular hemorrhage [5].

Different pathophysiological mechanisms are involved in injuring the premature brain, in particular infectioninflammation, pre- and/or postnatal malnutrition, and abnormalities in systemic and cerebral haemodynamics and oxygen supply. Preventative measures are key to reduce neurological morbidities in an extremely preterm population and research projects are focusing on the possibility to stabilize cerebral oxygenation in the first days of life through the application of cerebral near-infrared spectroscopy oximetry and implementation of clinical treatment guidelines in order to reduce the risk of brain damage [6].

Published: 11 August 2014

\section{References}

1. Figueras F, Cruz-Martinez R, Sanz-Cortes M, Arranz A, Illa M, Botet F, CostasMoragas C, Gratacos E: Neurobehavioral outcomes in preterm, growthrestricted infants with and without prenatal advanced signs of brainsparing. Ultrasound Obstet Gynecol 2011, 38:288-94.

2. Damodaram M, Story L, Kulinskaya E, Rutherford M, KUMAR S: Early adverse perinatal complications in preterm growth-restricted fetuses. Austr New Zeal J Obstet Gynecol 2011, 51:204-209.

3. Been JV, Zimmermann LJl: Histological chorioamniositis and respiratory outcome in preterm infants. Arch Dis Child Fetal Neonatal Ed 2009, 94: F218-25.

4. Te Pas $A B$, Walther FJ: A randomized, controlled trial of delivery-room respiratory management in very preterm infants. Pediatrics 2007, 120:322-329.

5. Oh W, Fanaroff AA, Carlo WA, Donovan EF, McDonald SA, Poole WK, Eunice Kennedy Shriver National Institute of Child Health and Human Development Neonatal Research Network: Effects of delayed cord clamping. J Perinatol 2011, 31(Suppl 1):S68-71.

6. Hyttel-Sorensen S, Austin T, van Bel F, Benders M, Claris O, Dempsey E, Fumagalli M, Greisen G, Grevstad B, Hagmann C, Hellström-Westas L, Lemmers P, Lindschou J, Naulaers G, van Oeveren W, Pellicer A, Pichler G, 
Roll C, Skoog M, Winkel P, Wolf M, Gluud C: A phase II randomized clinical trial on cerebral near-infrared spectroscopy plus a treatment guideline versus treatment as usual for extremely preterm infants during the first three days of life (SafeBoosC): study protocol for a randomized controlled trial. Trials 2013, 14:120

doi:10.1186/1824-7288-40-S1-A9

Cite this article as: Mosca et al.: The management of extremely preterm infants. Italian Journal of Pediatrics 2014 40(Suppl 1):A9.

Submit your next manuscript to BioMed Central and take full advantage of:

- Convenient online submission

- Thorough peer review

- No space constraints or color figure charges

- Immediate publication on acceptance

- Inclusion in PubMed, CAS, Scopus and Google Scholar

- Research which is freely available for redistribution

Submit your manuscript at www.biomedcentral.com/submit
() Biomed Central 